\title{
Risk Assessment for Chemical Substances: The Link Between Toxicology and Public Health ${ }^{1,2}$
}

\section{Avaliação de Risco de Substâncias Químicas: O Elo entre a Toxicologia e a Saúde Pública}

\author{
Francisco J. R. Paumgartten ${ }^{3}$ \\ PAUMGARTTEN, F. J. R. Risk Assessment for Chemical Substances: The Link between \\ Toxicology and Public Health. Cad. Saúde Públ., Rio de Janeiro, 9 (4): 439-447, oct/dec, 1993. \\ Virtually all chemical substances may cause adverse health effects, depending on the dose and \\ conditions under which individuals are exposed to them. Toxicology - the study of harmful \\ effects of chemicals on living organisms - provides the scientific data base on which risk \\ assessment of adverse health effects stands. Risk assessment (RA) is the process of estimating \\ the probability that a chemical compound will produce adverse effects on a given population, \\ under particular conditions of exposure. Risk assessment process consists of four stages: Hazard \\ Identification (HI), Exposure Assessment (EA), Dose-Response Assessment (DRA), and Risk \\ Characterization $(R C)$. The risk assessment process as a whole makes it possible to carry out \\ cost(risk)/benefit analysis, and thus risk management, on a rational basis. A capacity to \\ undertake risk assessment is thus sine qua non for making decisions that are concerned with \\ achieving a balance between economic development and adequate protection of public health \\ and the environment.
}

Key words: Toxicology; Risk Assessment; Risk Management; Cancer; Public Health; Economic Development; Developing Countries

\section{AIMS AND APPROACHES OF MODERN TOXICOLOGY}

"What is there that is not a poison? All things are poison and nothing [is] without poison. Solely the dose determines that a thing is not a poison." The Third Defense (Paracelsus, 1492-1541)

"What is there that is not a poison? All things are poison...". This statement, written nearly five centuries ago, suggests that Paracelsus tended towards a surprisingly modern view of the phenomenon of toxicity.

\footnotetext{
${ }^{1}$ This article is dedicated to the memory of Prof. Dr. Roberto Alcântara Gomes, the founding father of genetic toxicology in Brazil.

${ }^{2}$ Researcher funded by CNPq (Proc. 300947/89-5).

${ }^{3}$ Department of Pharmacology and Toxicology. The National Institute for Health Quality Control, Oswaldo Cruz Foundation. Av. Brasil 4365, Rio de Janeiro, RJ, 21045-900, Brazil.
}

Paracelsus saw toxicity not as an attribute of a restricted group of substances called poisons, but as a general property of all substances. Viewed from a different angle, this general statement carries a complementary implication: the expression of toxicity - regardless of whether or not a thing is a so-called poison - depends in part on factors that are extraneous to the inherent nature of the substance, for example on the dose to which an individual has been exposed.

Thus, both for Paracelsus and for modern toxicologists, it makes no sense to classify chemical substances as toxic or non-toxic. Toxicity and non-toxicity only exist in relation to the conditions under which an individual is exposed to a compound. As such, toxicology is concerned with the entire universe of chemical compounds, and its aim - the study of toxicity - can be understood as being centered not only on mechanisms, but on all factors that determine toxic phenomena. 
Another interesting aspect of Paracelsus 's statement is that it uses a negative rather than a positive definition: "Solely the dose determines that a thing is not a poison" (Deichmann et al., 1986). This suggests that, like modern toxicologists, he tended to take a top-down view of the relation between dose and toxic effect. If all substances are potentially toxic, and if toxicity depends on dose, there must always be a "toxicity threshold"; in other words, a limiting dose below which a substance is no longer a "poison". This is the standpoint from which today"s toxicologists approach the phenomenon of toxicity. To assess the risks arising from human exposure to a given substance, they attempt to establish the lower limits of toxicity, the NOAEL ("No Observed Adverse Effect Level"), in experimental studies. Since the final objective is not to determine the risk of adverse effects on laboratory animals, but on humans, a process of extrapolation is also necessary to establish a permissible level of exposure for humans.

To be on the safe side, taking into account inter- and intraspecies variations, extrapolation involves dividing the experimentally determined NOAEL by an arbitrary factor of safety (or uncertainty). In the case of substances for which there exist data on chronic human exposure, a factor of ten is generally used, to compensate for variability between different individuals, thereby protecting the small number of people that may be specifically susceptible to a toxic effect. Where there is no such data, a factor of 100 is generally used (10 to cover extrapolation between species, and 10 to cover differences between individuals).

It is worth remembering that this approach ceases to make sense in cases where scientific evidence suggests that a threshold effect does not exist. Such a situation may arise, for example, with substances that bind to DNA and cause mutations in genetic material. In theory, a single molecule from a chemical carcinogen could lead to a mutation, thereby unleashing a series of events that resulted in the formation of a tumor. This possibility, although remote, is sufficient to raise questions regarding the validity of the threshold model. In cases such as this, use is made of another model known as linear extrapolation of risk. This model is based on the assumption that any quantity of a given substance could cause a particular toxic effect, and that the probability of such an occurrence taking place is directly proportional to the dose.

Thus, toxicologists do not simply indicate whether a substance is toxic or non-toxic, or whether it is extremely or only slightly toxic. These categories, as we have seen, do not make a great deal of sense. Rather, it is the toxicologist's role to map out the nature of risk, tracing its contours within a framework in which toxicity is seen more as a nuance than as a precise measure.

\section{ASSESSMENT OF TOXICOLOGICAL RISK: A RATIONAL BASIS FOR DECISION-MAKING IN PUBLIC HEALTH}

Risk assessment - in other words, the process of estimating the probability that a chemical substance will cause adverse effects on a given population, under particular conditions of exposure - provides the rational basis for public health decisions and actions aimed at reducing or eliminating the risk concerned. This assessment allows health administrators - on whose shoulders, in the final analysis, responsibility for risk management must fall — to weigh the risks to human health and the costs of reducing those risks, against the benefits arising from the use of the chemical substance in question. Thus, risk management does not merely involve reaching conclusions on the basis of risk assessment; it also includes developing alternatives to a chemical agent, and comparing the available options, as well as taking due account of any ethical, political and socioeconomic considerations that may be relevant.

While risk assessment is a fundamentally scientific exercise, risk management together with decisions relating to acceptable levels of risks in a given population under any particular set of conditions - is a 
process that reaches beyond the realms of science. The question of what is or is not acceptable, of what risks a given society is prepared to run, must always be a matter of subjective judgement, as conditioned by specific local circumstances. As such, risk management in Brazil, and in South America as a whole, is governed by cultural and socioeconomic conditions that are entirely different from those found in developed countries. Even within the continent itself, or within the borders of a large country such as Brazil, there are marked regional differences in this regard. A risk may be considered acceptable in one context, but unacceptable in another. It is therefore not surprising that, in South America, public health decision-makers have to assign values on both sides of the scales (costs/risks versus benefits) in a way that is quite different to costumary practice in the United States or Europe.

\section{Reliability of Risk Estimates}

Despite increasing reliance on risk estimates for decision-making, the reliability of risk assessment depends, to a great extent, on the adequacy and completeness of the scientific data base on which it is based. Since every necessary piece of information is not available for each and every substance requiring a risk assessment, and since there are too many relevant chemicals to be evaluated, ideal data bases can hardly, if ever, be obtained. On pragmatic grounds, risk assessors make use of a certain number of assumptions so as to bridge the data gaps they face during the risk assessment process. The larger the data gap, the longer and riskier is the bridge between the scientific data base (evidence) and the risk estimates used in risk management. The more unrealistic the assumptions that are made, the greater is the uncertainty surrounding the estimation of risk. This uncertainty can be reduced if more adequate and complete data bases are used. In situations where assumptions remain unavoidable, studies aimed at validating them should be performed, if feasible. Moreover, risk estimates should be accompanied not only by a summary of any relevant biological information that is available, but also by an account of the assumptions used plus their limitations, and a critical evaluation of the uncertainties (both qualitative and quantitative) in the risk assessment.

In recent years, there has been much concern with regard to the uncertainties in risk assessment (Gregory, 1990). Lack of accuracy in risk estimates may have two consequences. If risk is underestimated, and protective measures are not adequate, a higher incidence of adverse health effects is likely to occur in the exposed population. On the other hand, if risk is overestimated, the socioeconomic costs of stringent protective measures - eventually leading to unemployment, decreases in economic activity, and so on - are higher than the costs of less drastic measures that would have been sufficient to provide the same intended level of health protection. Thus, conservative estimates of risk (overestimation) eventually lead to increases in the costs of risk management.

The usual way of compensating for the uncertainties in the risk assessment process is to make use of arbitrary safety factors when quantitative limits for human and environmental exposure are to be set. Thus, an allowance is made in order to stay on the safe side, even in the case of error.

However, there are many public health and economic reasons for attempting to achieve greater precision in risk assessment. Consequently research capacity should be directed towards reducing the degree of uncertainty surrounding the assumptions that underlie the risk assessment process.

It is important to stress that the relative costs of a conservative risk estimate for an affluent society, and for a society with poor health standards and limited financial resources, are very different. Inappropriate use of funds for one purpose means that, elsewhere, an urgently needed health program will remain without finance and populations will suffer. Thus, generous use of conservative approaches, in compensation for a lack of specific scientific data, seems to be a privilege that developing countries can ill afford. This means that, for South American 
toxicologists, who have only recently been given the responsibility for determining health risk assessments, reliability and accuracy should be regarded as priorities of the utmost importance, from the outset.

\section{Scientific Basis for Risk Assessment of Adverse Health Effects}

The risk assessment process, as it is currently conducted, consists of four elements (NAS, 1983), which are: hazard identification (HI), exposure assessment (EA), dose-response assessment (DRA), and risk characterization (RC) (Figure 1).

\section{Hazard Identification}

Hazard identification is the first stage and is concerned with characterizing the nature and strength of the evidence for causation from studies in laboratory animals and/or human beings. HI should eventually provide an answer to the question: Does exposure to the chemical agent cause adverse health effects?

Data from animal experimentation, in which I would also include in vitro assays, and human data from epidemiological studies, form the scientific basis for the HI segment of risk assessment.

Since epidemiological studies are concerned with the actual occurrence of adverse health effects in humans, they have the advantage of obviating the need for animal to human extrapolation, which is one of the major sources of uncertainty in risk estimates. There are other advantages as well, for example the fact that epidemiological studies investigate human beings in their natural environment, under the influence of a range of factors such as alcohol consumption, smoking habits, nutritional differences, and so on, which may interact with the biological effects of the chemical agent, and may also contribute to the occurrence of the adverse effect. In animal studies it is quite difficult, if not impossible, to take into account all the variables that may or may not be relevant to the occurrence of the adverse reaction in humans.
On the other hand, an inherent limitation of the epidemiological approach is that it can never provide evidence of adverse health effects in advance of human exposure to the chemical agent. In other words, epidemiological studies can only be carried out either when human exposure occurs, or when it has already occurred. In addition, there are two further limitations to the epidemiological approach in risk assessment. First, there is the difficulty of isolating the effect of a single substance from the effects of the combined exposures that occur in real life (e.g., air pollution); this is the other side of the coin with respect to the advantages mentioned earlier. The second limitation is the lack of precise quantitative data on exposures that have occurred in the past, a fact which usually keeps the utility of cohort studies within the limits of hazard identification, precluding their further use in quantitative risk assessment (Swaen, 1988).

Owing to its limitations, the epidemiological approach itself is rarely sufficient to establish cause and effect relationships. Consequently, even when human data are available, complementary experimental data on animals are usually required for the purposes of hazard identification. Furthermore, there are many cases in which, for ethical reasons, assessment of safety in animals must precede human exposure, for instance during the development of new drugs, pesticides, or food additives.

Whenever risk assessors are confronted with the problem of extrapolating the human situation from animal data, they are dealing with an unavoidable source of uncertainty in risk assessment (Voisin et al., 1990). One of the assumptions used as a basis for extrapolation is that toxic effects are comparable between different species, for similar concentrations of a substance or its metabolites in blood. A more refined version of this assumption relates toxic effects to concentrations, not in blood, but in target organs or tissues. However, although pharmacokinetic data are indispensable if animal studies are to have any predictive value, there is no way round the fact that interspecies differences in toxic responses are 

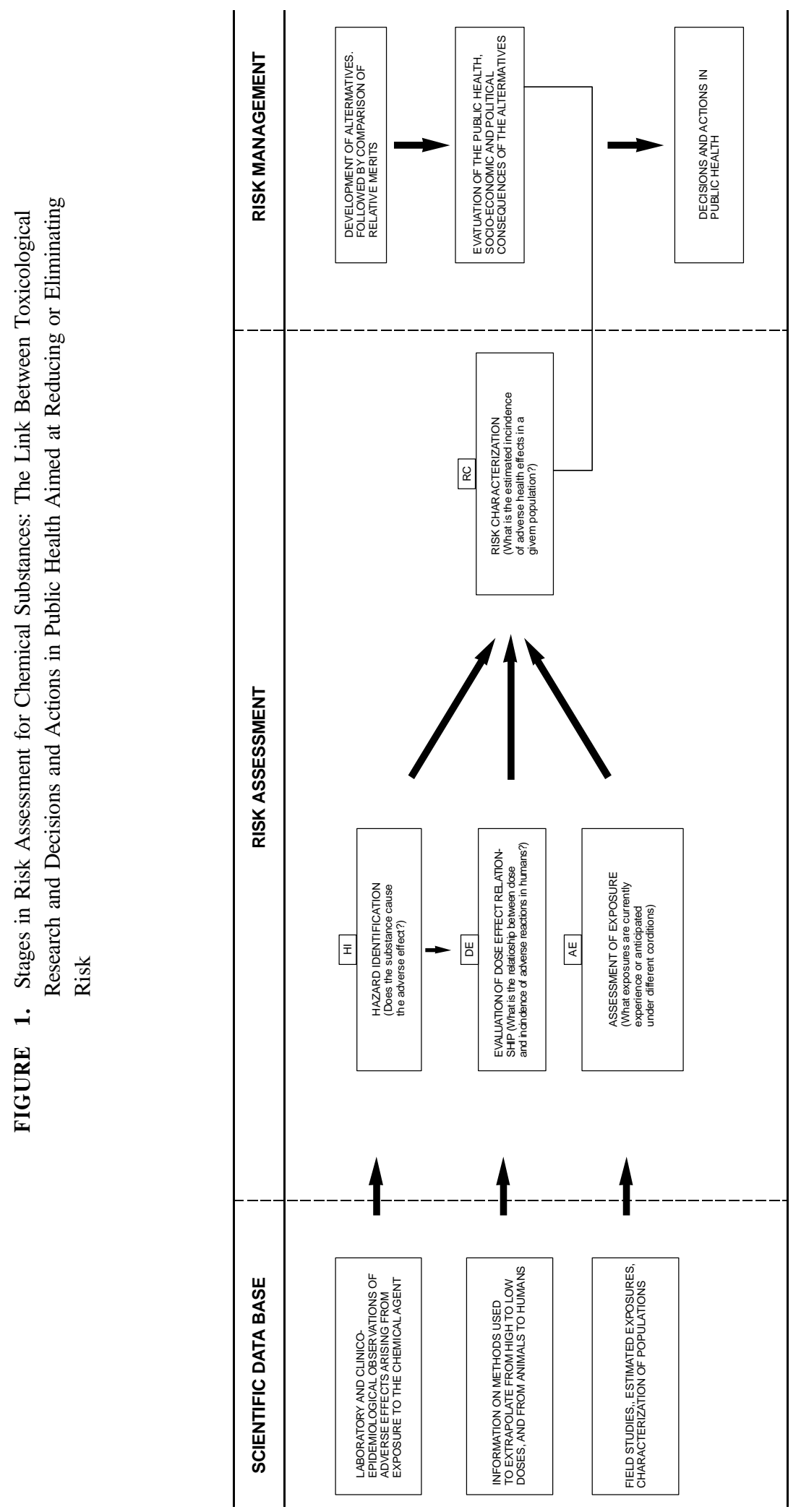

0
0
0
0
$z$
$\vdots$
0
0
0
0
0
0
0
0
0
0
0 
highly complex. These responses are not due only to the pharmacokinetic variables mentioned here, but also to a whole range of other factors that are still not fully understood.

\section{Assessment of Exposure}

Assessment of exposure is concerned with estimating the amount of a substance that is taken up or absorbed by human beings following exposure (actual or anticipated) by different routes (portals of entry). The length of the exposure time and the number of individuals exposed, or yet to be exposed, are parameters that also need to be taken into account. Assessment of exposure should be carried out in such way as to answer the folllowing question: What levels of exposure are currently being experienced by individuals, or can be anticipated for those individuals, under different conditions?

The task of estimating what dose of a given chemical substance has been absorbed by an individual is a complex one. It involves taking into account all the potential sources of exposure, via water, air, soil and food. Biotic and abiotic degradation, persistence and accumulation in the environment, ingestion of contaminated soil and pasture by cattle, rate of particle deposition, absorption through skin, bioaccumulation in the food chain, human pharmacokinetics, changes in diet and levels of exposure over a lifetime, are just a few of the factors that need to be considered, demonstrating the enormous complexity of the task. Sometimes indirect routes are more important than more direct and obvious ones. One example is the contamination of humans by dioxins present in emissions of garbage incinerators: dioxin contamination in the food chain carries risks that are 200 to 500 times greater than those resulting from inhalation, the more direct route of exposure to the pollutant (Stevens \& Gerbel, 1988). Thus, in the case of dioxins, and possibly also in the case of other non-volatile compounds present in emissions, individuals are more at risk from contamination that has occurred in areas where food is produced, than from pollution in residential zones.
It is interesting to note that assessment of exposure is concerned with specific scenarios, and that these have a direct bearing on assessment of risk. Thus, if a risk assessment for a particular chemical substance is carried out on the basis of an exposure scenario in a European country, it may well be inadequate for a developing country. The quantity of (contaminated) earth ingested by a Brazilian child is certainly different to that ingested by a European or American child, and the same is true of the food consumption, not to mention innumerable other factors.

This kind of situation can arise with drugs as well as with pollutants. The exposure of pregnant Brazilian women to misoprostol, a prostaglandin E1 analogue whose abortive properties encourage its illicit use, is higher than would be the case in a country which allowed abortion and which controlled pharmaceutical sales more efficiently (Paumgartten et al., 1992).

\section{Dose-Effect Relationship}

This stage involves evaluation of the relationship between the dose of the chemical substance and the anticipated incidence of the adverse effect in the exposed population. During this phase of risk assessment, the question to be answered is: What is the relationship between the dose and the incidence of the adverse reaction in humans?

One of the most controversial aspects of the dose-effect relationship models used in risk assessment is the assumption - one that underpins the utilization of safety factors that there exists such a thing as a threshold dose below which no toxic effect occurs. There are a number of chemical substances, in particular genotoxic carcinogenic agents, for which there are good reasons to believe that this assumption is not valid (Perera, 1984). The idea that carcinogenic substances carry a risk, irrespective of how far the dose is reduced, was proposed as early as the 1960 's. For these substances, Mantel \& Bryan (1961) suggested an approach that, while taking into account the notion that any dose might imply risk, nonetheless established the 
concept of a virtually safe dose (VSD); in other words, a dose that was too low to warrant concern. This conservative approach was subsequently incorporated into various new mathematical models, which have since been widely adopted by regulatory agencies responsible for the control of potentially carcinogenic substances. More recently, many toxicologists have questioned the use of models that involve this kind of low dose extrapolation. Drawing on epidemiological studies of individuals subject to occupational exposure, they argue that this approach leads to gross overestimation of risk. Others, meanwhile, argue that, given the relatively small sample size used in these epidemiological studies and other methodological limitations, the available evidence is insufficient to overturn estimates made using the conservative models.

\section{Risk Characterization}

Risk characterization stands on the three previous stages and constitutes the outcome of the risk assessment process as a whole. Data gathered and analyzed in the three earlier stages are assembled, integrated and summarized, and conclusions on the risk of adverse health effects are drawn. Risk characterization should provide information on risk estimates in a form that is useful and easily understood by those who are responsible for making decisions on matters of public health. The general question to be answered at this final stage is: What is the estimated incidence of adverse health effects in a given population, under specific conditions of exposure? However, as emphasized by Preuss \& Ehrlich (1987) and Paustenbach (1989), the answer to this question must always be qualified. That is to say, it must be accompanied by a summary that lays out all the relevant available biological information, the assumptions used and the limitations of these assumptions, together with a critical analysis of any areas of uncertainty (both qualitative and quantitative).

\section{Risk Assessment: \\ A Prerequisite for Decisions that Aim to Achieve a Proper Balance between Economic Development and Protection of Health and the Environment}

Risk assessment makes it possible to carry out cost(risk)/benefit analysis, and thus risk management, on a rational basis. A capacity to undertake risk assessment is thus sine qua non for any country wishing, in an independent and efficient fashion, to make decisions that are concerned with achieving a balance between economic development and adequate protection of public health and the environment.

The chemical-pharmaceutical industry can only develop new medicinal drugs, food additives, pesticides and the like, if it has the capacity to assess the risk that any of these products might represent for human health and the environment. In addition, national regulatory agencies must be competent to carry out a critical analysis of documentation, submitted by the industry, that reports on the results of risk assessments for new products. These agencies, in other words, must be able to come to independent decisions. Equally, it should be recognized that industrial growth results in environmental pollution, whose control, by raising production costs, will inevitably have an effect on economic activity.

The more rigorous the regulatory apparatus, and the lower the maximum admissible limits for a given pollutant, the greater the burden arising from pollution control measures. The graph in Figure 2, based on data provided by Anderson (1987), gives a clear illustration of this point. The cost of decontaminating an area polluted with dioxins from a nearby municipal garbage incinerator increases with the rigour of the standards used in setting targets for reduction in soil pollutant levels. There is symmetry between the curve of rising costs and the curve of declining risks. It is interesting to note that, as the process of decontamination approaches the point of complete pollutant elimination ( $0 \mathrm{ppm})$, costs rise even more rapidly, while risks decline even more slowly. In other words, equivalent 
FIGURE 2. Decontamination of an Area Polluted with Dioxins: Relationship between the Level of Risk Reduction and the Costs Involved in Achieving a Given Standard

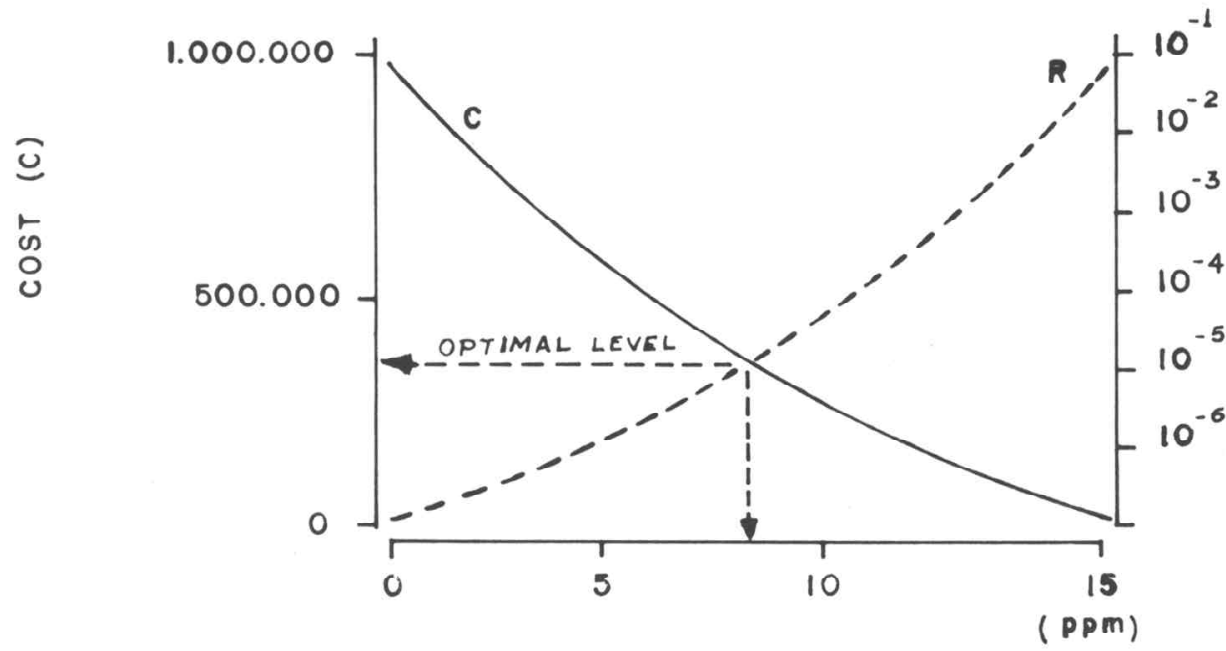

\section{LEVEL OF DECONTAMINATION}

Source: based on Anderson, 1987, and on Paustenbach, 1989.

reductions in risk become more and more expensive. A brief appraisal of the graph in Figure 2 suggests that, in terms of benefits and costs, the optimal level of decontamination coincides with the intersection of the two curves. The advantage of risk assessment is that it provides the administrator with this type of analysis at the moment when decisions must be made, for example when decontamination standards must be set for a given polluted area.

In developing countries of continental dimensions, such as Brazil, the challenge of achieving a balance between economic development and adequate protection of public health and the environment, requires a capacity to manage the risks arising from chemical substances on a rational basis. As such, the development of the study of toxicology, and the creation of regulatory agencies capable of assessing this type of risk, should be seen as strategic objectives.

\section{ACKNOWLEDGMENTS}

The author's sincere thanks go to Iris Silva Grimaldi for her help during preparation of this manuscript.

\section{RESUMO}

PAUMGARTTEN, F. J. R. Avaliação de Risco de Substâncias Químicas: O Elo entre a Toxicologia e a Saúde Pública. Cad. Saúde Públ., Rio de Janeiro, 9 (4): 439-447, out/dez, 1993.

Virtualmente todas as substâncias químicas podem causar efeitos adversos, dependendo da dose e das condições em que os indivíduos são a elas expostos. A toxicologia, isto é, o estudo dos efeitos danosos de substâncias químicas em organismos vivos, fornece a base de dados científicos na qual se apoia a avaliação de risco de efeitos adversos para a saúde. Avaliação de Risco (AR) é o processo de se estimar a probabilidade que um composto químico tem de vir a produzir efeitos adversos numa dada população, em determinadas condições de exposição. A avaliação de risco consiste de quatro estágios: identificação da periculosidade (IP); avaliação da exposição (AE); avaliação da relação dose-efeito (ADE); e caracterização do risco (CR). O processo de avaliação de risco como um todo possibilita a realização da análise custo (risco)/benefício e, portanto, do gerenciamento do risco, em bases racionais. A 
capacidade de se realizar a avaliação de risco é, assim, condição sine qua non para a tomada de decisões que estejam voltadas para se alcançar um equilíbrio entre desenvolvimento econômico e uma adequada proteção da saúde pública e do meio ambiente.

Palavras-Chave: Toxicologia; Avaliação de Risco; Gerenciamento do Risco; Câncer; Saúde Pública; Desenvolvimento Econômico; Saúde Ambiental

\section{REFERENCES}

ANDERSON, S. A., 1987. Quantifying uncertainty in municipal solid waste incinerator risk assessments. In: Annual Meeting of the Society for Risk Analysis, A bstracts, MPM-B2.

DEICHMANN, W. B.; HENSCHLER, D.; HOLMSTEDT, B. \& KEIL, G., 1986. What is there that is not a poison? A study of the Third Defense by Paracelsus. A rchives of Toxicology, 58: 207-213.

GREGORY, A. R., 1990. Uncertainty in health risk assessments. Regulatory Toxicology and Pharmacology, 11: 191-200.

MANTEL, N. \& BRYAN, W. A., 1961. "Safety" testing of carcinogenic agents. Journal of the National Cancer Institute, 27: 455-460.

NAS (National Academy of Sciences), 1983. Risk Assessment in the Federal Government: M anaging the Process. Washington, DC: National Academy Press.
PAUMGARTTEN, F. J. R.; CASTILlA, E. E.; MONTELEONE-NETO, R.; COELHO, H. L. L. \& COSTA, S. H., 1992. Risk assessment in reproductive toxicology as practiced in South America. In: Risk Assessment of PrenatallyInduced Adverse Health Effects (D. Neubert, R. J. Kavlock, H-J Merker \& J. Klein, eds.), pp. 163-179, Berlin, Heidelberg, New York: Springer-Verlag.

PAUSTENBACH, D. J., 1989. Important recent advances in the practice of health risk assessment: Implications for the 1990's. Regulatory Toxicology and Pharmacology, 10: 204-243.

PERERA, F. P., 1984. The genotoxic/epigenetic distinction: Relevance to cancer policy. Environmental Research, 34: 175-191.

PREUSS, P. W. \& EHRLICH, A. M., 1987. The Environmental Protection Agency's risk assessment guidelines. Journal Air Pollution Control, 37: 784-791.

STEVENS, J. B. \& GERBEL, E. N., 1988. Dioxin in the agricultural food chain. Risk Analysis, 8: 329-335.

SWAEN, G. M. H., 1988. The use of epidemiological data in risk assessment. Regulatory Toxicology and Pharmacology, 8: 422-430.

VOISIN, E. M.; RUTHSATZ, M.; COLLINS, J. M. \& HOYLE, P. C., 1990. Extrapolation of animal toxicity to humans: Interspecies comparisons in drug development. Regulatory Toxicology and Pharmacology, 12: 107-116. 